AN ESTIMATE OF THE SIGNALS APPEARING AT THE INPUT TO

THE AGS BOOSTER BEAM POSITION MONITORING SYSTEM

BOOSTER TECHNICAL NOTE

NO. 170

D. J. CIARDULLO

JULY 11, 1990

ALTERNATING GRADIENT SYNCHROTRON DEPARTMENT BROOKHAVEN NATIONAL LABORATORY

UPTON, NEW YORK 11973 


\title{
AN ESTIMATE OF THE SIGNALS APPEARING AT THE INPUT TO \\ THE AGS BOOSTER BEAM POSITION MONITORING SYSTEM
}

\author{
D. J. CIARDULLO
}

\section{INTRODUCTION}

Each BPM station of the AGS Booster consists of an electrostatic detector, along with associated processing and acquisition electronics. A beam bunch passing within the detector induces charge onto its pick-up electrodes, resulting in a pair of "bunch signals". These voltages are related to the instantaneous charge encircled by the detector, and can be processed to determine the transverse position of the bunch within the beampipe (horizontal or vertical). Amplitude and frequency compensation are accomplished through the Front End Processing module of the BPM electronics. This circuitry must be of sufficient bandwidth and dynamic range to accommodate any bunch signals which might result from the variety of particles accelerated in the Booster.

The purpose of this technical note is to provide estimates for the bandwidth and peak voltage of a "typical" detected beam bunch, after bunching has already occurred. These estimates will be based on the expected beam intensities listed in the Booster Design Manual for protons, polarized protons and heavy ions.

\section{APPROXIMATIONS AND ASSUMPTIONS}

The following approximations and assumptions are made with respect to the bunch signal calculations in this technical note:

1. The "bunching factor" is a number less than or equal to unity which results from the ratio of the linear charge density of a dc beam to the peak charge density after bunching.

2. The longitudinal charge distribution of the bunch is assumed to have a shape described by $\cos ^{2} x$, where $x$ represents a scaled parameter of the RF phase such that $x$ goes from $-\pi / 2$ to $+\pi / 2$ over the bunch width.

3. The transverse charge distribution in a bunch is approximated to be symmetric.

4. Most of the energy in a $\cos ^{2} x$ pulse is contained within the band $|f|<=1 / t$ of its spectral density. As such, the spectral width of the detected bunch signals is taken to be $f=1 / t$ (zero crossing bandwidth) ${ }^{2}$. 
5. It is assumed that during the bunching process, no loss of charge occurs, and the total charge is divided equally amongst the bunches.

\section{CALCULATION OF SIGNAL BANDWIDTH}

\section{DEFINITION OF THE BUNCH:}

If the total charge occupying the Booster were to be evenly distributed over its circumference, then the linear charge density of the beam would be

$$
A_{d c}=\frac{Q}{201.78} \text { coulombs/meter }
$$

where: $Q$ is the total charge in the ring and 201.78 is the circumference (in meters) of the Booster ${ }^{\prime}$.

Let $h$ represent the harmonic number of the Booster. After bunching occurs, there will be $h$ bunches, each of charge $Q_{b}$ :

$$
Q_{b}=\frac{A_{d c}(201.78)}{h}=0.5 A_{b} L \text { coulombs }
$$

The right hand side of equation (2) is the area beneath the $\cos ^{2} x$ signal which results from a detected beam bunch. Its width is $L$ meters, and $A_{b}$ is the peak charge density of the bunch (see Figure 1). Taking the ratio of both charge densities yields an expression for the bunching factor in terms of the physical length of the bunch:

$$
B=\frac{A_{d c}}{A_{b}}=0.5 \frac{h L}{201.78}
$$

Equation (3) can be rewritten in terms of $t_{o}$ (the temporal bunch width) and $f_{r f}$ (the bunch repetition frequency):

$$
B=\frac{L / 2}{T_{r f}}=\frac{t_{0}}{2} f_{r f}, \quad t_{0}=\frac{2 B}{f_{r f}}
$$




\section{SIGNAL BANDWIDTH ESTIMATE}

If the spectral bandwidth of a $\cos ^{2} x$ pulse is approximated as the first zero crossing of its power spectrum ${ }^{3}$, then

$$
B W=\frac{2}{t_{o}}=\frac{f_{r f}}{B} \mathrm{~Hz}
$$

where BW is the approximate bandwidth required to process the bunch signal and $B$ is the bunching factor $(<1)$. Insufficient BPM signal processing bandwidth implies an absolute position accuracy which depends on the amount of beam bunching. From the perspective of the BPM end user, a beam whose position is not actually changing would appear to move as the RF sweeps up in frequency. This dependency is removed if the BPM front end has "enough" bandwidth (approximated by [5]) to accommodate the maximum bunching expected in the Booster. For example, using an RF frequency of $4.11 \mathrm{MHz}$, a bunch factor of $1 / 5$ would require a minimum signal processing bandwidth of $20 \mathrm{MHz}$ (which is the design value for the electronics). One should keep in mind, however, that this value is only an estimate, since both the bunch signal shape and its spectral bandwidth are approximations.

\section{MAXIMUM VOLTAGE CALCULATION}

For a given particle type (i.e., protons, polarized protons or heavy ions) there is some maximum instantaneous voltage which will appear at the detector plates. It is necessary to know this signal amplitude in order to determine the appropriate gain scaling required of the BPM electronics.

The peak voltage on a particular PUE (the electrode within the detector formed by onehalf of a diagonally split cylinder) depends on its total effective capacitance $\left(C_{\text {load }}\right)$, as well as the maximum instantaneous charge $\left(Q_{\text {pue }}\right)$ induced on it. For a centered beam,

$$
V_{0}(\max )=\frac{Q_{\text {pue }}}{C_{\text {load }}}=\frac{Q_{\text {det }} / 2}{C_{\text {load }}} \text { Centered beam, voltage on one electrode }
$$

Note that for a centered beam, $Q_{\text {pue }}$ is one half of the total charge encompassed by the BPM detector $\left(Q_{d e t}\right)$. Also, $C_{\text {load }}$ is the capacitive load used to determine the voltage on one electrode (i.e., $Q_{\text {pue }}$ sees $C_{\text {load }}$, while $Q_{d e t}$ sees $2 C_{\text {load }}$ ). 


\section{CAPACITIVE LOADING ESTIMATE}

The total capacitive load used to determine the voltage on a PUE is influenced by the following (refer to Figure 2):

$C_{p u e}:$ The effective electrode capacitance resulting from the combination of electrode, feedthrough, stray and inter-electrode capacitances within the detector. Note (from Figure 2) that this value is only part of the total capacitance seen by the charge on one PUE.

$C_{i s}$ : The capacitance to ground of the thermal isolator and its connectors.

$C_{c}$ : The total capacity of the 10 -foot cable assembly used to connect the detector to the front end of the BPM system, including its connectors.

$C_{f e p}$ : The total front end capacitance seen looking into the input of the BPM electronics. This value is increased during the BPM system's "divide by 10 " mode of operation.

The capacitive loading for one electrode is then

$$
C_{\text {load }}=C_{p u e}+C_{i s}+C_{c}+C_{f e p}
$$

The value of $C_{\text {load }}$ changes only when the BPM Front End Processing module is put into the "divide by 10 " mode. In this case, $C_{\text {fep }}$ (and hence $C_{\text {load }}$ ) is increased to effect the desired 20 $\mathrm{dB}$ signal attenuation.

\section{MAXIMUM INSTANTANEOUS CHARGE WITHIN THE DETECTOR}

The total charge contained in one bunch $\left(Q_{b}\right)$ is

$$
Q_{b}=\frac{(\text { ions } / \text { pulse }) \times(\text { charges/ion }) \times\left(1.6 \times 10^{-19}\right)}{(\text { bunches } / \text { pulse })} \text { coul. }
$$

Table 1 shows the expected total charge for protons, polarized protons and various ions to be accelerated in the Booster. These values are based on information obtained from the Booster Design Manual ${ }^{!}$.

Since the longitudinal charge distribution for each bunch is assumed to be $\cos ^{2} x$, the resulting "bunch signals" at the BPM electronics (after frequency equalization) will be pulses of 
the same shape. In addition, the area beneath the pulse (eq. 2) is related (within a constant) to the total charge within the bunch. Equations (2) and (3) can be used to obtain an expression for the longitudinal charge density:

$$
A_{b}=\frac{Q_{b}}{L / 2}=\frac{Q_{b}}{B(201.78 / h)} \text { coul } / \text { meter }
$$

Equation (9) can now be used to determine the peak instantaneous charge passing between a set of pick-up electrodes. The maximum total charge on the plates will occur when the bunch is longitudinally centered within the detector (see Figure 3). Since the detector length is 0.21 meters, the maximum total charge enclosed by both electrodes $\left(Q_{d e t}\right)$ is:

$$
\begin{aligned}
Q_{\text {det }}= & \int A_{b} \cos ^{2}\left[\frac{\pi}{2} \frac{h}{201.78 B} x\right] d x \\
& -0.21 / 2
\end{aligned}
$$

(see Appendix A). Using a table of integrals ${ }^{4}$, (11) can be rewritten as

$$
Q_{d e t}=Q_{b}\left[\frac{0.105}{B(201.78 / h)}+\frac{1}{\pi} \sin \left(\pi \frac{0.105}{B(201.78 / h)}\right)\right]
$$

where: $\quad Q_{d e t}$ is the total maximum instantaneous charge in the detector, $Q_{b} \quad$ is the total charge within the bunch,

$B$ is the bunching factor $(<1)$,

$h \quad$ is the harmonic number, and

201.78 and 0.21 are constants (the Booster circumference and BPM detector length in meters, respectively). 
Equations (6) and (12) can be combined to find the voltage on one electrode for a centered beam $\left(V_{o}\right)$ :

$$
\begin{aligned}
V_{0} & =\frac{Q_{\text {del }} / 2}{C_{\text {load }}} \\
& =\frac{Q_{b}}{2 C_{\text {load }}}\left[\frac{0.105}{B(201.78 / h)}+\frac{1}{\pi} \sin \left(\pi \frac{0.105}{B(201.78 / h)}\right)\right]
\end{aligned}
$$

\section{CONTRIBUTION OF DISPLACED BEAM TO MAXIMUM VOLTAGE}

Equation (12) gives the total charge encircled by both PUEs, and (13) gives the peak voltage on each plate for a centered beam. In general, however, the total charge is not divided equally among the two electrodes, but is dependent on the transverse beam location. The maximum voltage on one electrode occurs when the centroid of the beam is at the edge of the measurement aperture closest to it (see Figure 3BN). The expression which relates the voltages from the detector to the beam position is

$$
\text { Position }=M \frac{\left(V_{A}-V_{B}\right)}{\left(V_{A}+V_{B}\right)}+P
$$

where:

$$
\begin{aligned}
& M \quad \text { has been empirically determined to be on the order of } 100 \mathrm{~mm} \text {. } \\
& P \quad \text { is the position offset (in } \mathrm{mm} \text { ) due to differences in the mechanical } \\
& \text { and electrical center of the detector, and } \\
& V_{A} \text { and } V_{B} \text { are the PUE voltages. }
\end{aligned}
$$

When the beam is centered within the beampipe, then

$$
V_{A}=V_{B}=V_{o}
$$

If $M$ is taken to be $100 \mathrm{~mm}$ and $P$ is assumed negligibly small, then a beam position of $30 \mathrm{~mm}$ (at the measurement aperture edge closest to plate $A$ ) is found by rearranging eq. (14):

$$
V_{A}=1.86 V_{B}
$$


Given a constant beam intensity, if the beam moves from the center of the beam pipe to the aperture edge defined above, then the voltage of plate A will increase by $30 \%$ :

$$
\begin{aligned}
V_{A}+V_{B} & =2 V_{o} \\
V_{A} & =1.3 V_{o}
\end{aligned}
$$

Equation (17) indicates that the actual peak signal amplitude appearing on electrode A can be 1.3 times that of the voltage resulting from a (transversely) centered beam.

\section{SUMMARY}

Equations (6), (8), (13), and (17) can be combined to obtain an expression which relates the beam intensity to the maximum signal voltage expected on either pick-up electrode.

Given the number of particles per pulse and harmonic number, the charge contained in one bunch is known (8). The peak voltage on the PUEs (corresponding to the maximum instantaneous charge) occurs when the bunch is longitudinally centered within the detector. The amount of charge in the portion of the bunch encircled by the detector is used to determine the voltage on each electrode for a (transversely) centered beam (13).

Once the peak signal voltages are known for a centered beam, (17) is used to determine the maximum PUE voltage at the largest specified beam displacement $(30 \mathrm{~mm})$.

$$
V_{\max }=\frac{1.3 Q_{b}}{2 C_{\text {loud }}}\left[\frac{0.105}{B(201.78 / h)}+\frac{1}{\pi} \sin \left(\pi \frac{0.105}{B(201.78 / h)}\right)\right]
$$

Table 2 lists the maximum expected PUE voltages for various particles, based on information obtained from the Booster Design Manual. Also listed are the various capacitive elements which contribute to the plate loading capacitance $\left(C_{\text {load }}\right)$.

\section{CONCLUSIONS}

Equation (5) provides an approximation for the bandwidth of the bunch signals expected from the Booster beam position detectors. Equations (13) and (18) give the expected peak PUE voltages for a "zero" and a $+30 \mathrm{~mm}$ (edge of aperture) position, respectively. The estimates made are based on the intensities listed in the Booster Design Manual, as well as the approximations and assumptions previously listed. The BPM Front End Processing (FEP) electronics have been designed to provide three gain states $(\mathrm{x} 0.1, \mathrm{x} 1$ and $\mathrm{x} 10)$. Using Table 2 as a guide, these three gain settings can be used to maintain bunch signal amplitudes of $0.5<$ $\mathrm{V}_{\text {bunch }}<5$ Volts at the outputs of the FEP module. The amplitude upper limit is imposed by the 
data acquisition section of the BPM electronics (specifically, the Baseline restorer). In addition, the FEP module was designed with a bandwidth of $20 \mathrm{MHz}$, enough to process the signals resulting from a charge bunch 27 meters in length (full width) at a repetition frequency of 4.11 $\mathrm{MHz}$.

TABLE I. EXPECTED CHARGES

\begin{tabular}{|c|c|c|c|}
\hline ISOTOPE: & CHARGES PIRR ION" & 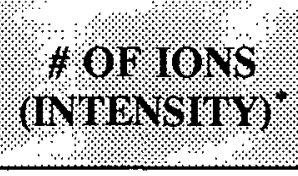 & $\begin{array}{l}\text { TOTAL" } \\
\text { charGE": } \\
\text { (COULOUBS) }\end{array}$ \\
\hline Protons & +1 & $1.5 \times 10^{13}$ & $2.4 \times 10^{-6}$ \\
\hline $\begin{array}{l}\text { Polarized } \\
\text { Protons }\end{array}$ & +1 & $\sim 1 \times 10^{11}$ & $3.2 \times 10^{-7}$ \\
\hline $\mathrm{C}$ & +6 & $\sim 5.4 \times 10^{10}$ & $5.2 \times 10^{-8}$ \\
\hline$S$ & +14 & $-1.5 \times 10^{10}$ & $3.4 \times 10^{-8}$ \\
\hline $\mathrm{Cu}$ & +21 & $\sim 1 \times 10^{10}$ & $3.4 \times 10^{-8}$ \\
\hline I & +29 & $\sim 6.6 \times 10^{9}$ & $3.1 \times 10^{-8}$ \\
\hline $\mathrm{Au}$ & +33 & $-3.2 \times 10^{9}$ & $1.7 \times 10^{-8}$ \\
\hline
\end{tabular}

* The "Charges Per Ion" and intensity values have been taken from the Booster Design $\underline{\text { Manual }}^{1}$, except for polarized protons, where $10^{11}$ seems to be a more widely accepted estimate.

For protons and heavy ions, this value is the total charge in all bunches occupying the Booster. For the case of polarized protons, this value assumes the accumulation of $10^{11}$ ions per linac pulse (occurring at a rate of $7.5 \mathrm{~Hz}$ ) over a period of 2.67 seconds (the non-accelerating portion of the Booster cycle). In either case, the total charge is used as a starting point for Table 2 below. 
TABLE 2. EXPECTED PEAK VOLTAGE (EACH PUE)"

\begin{tabular}{|c|c|c|c|c|c|c|}
\hline $\begin{array}{c}\text { ISO- } \\
\text { TOPE }\end{array}$ & $\begin{array}{c}\text { \# OF } \\
\text { BUNCHES } \\
\end{array}$ & $\begin{array}{l}\text { CHARGE }{ }^{* * *} \\
\text { PER BUNCH }\end{array}$ & $\begin{array}{c}\text { BUNCH } \\
\text { FACTOR } \\
\end{array}$ & $\begin{array}{c}Q_{\text {det }} \\
\text { (Coul) }\end{array}$ & $\begin{array}{c}V_{\text {peak }} \\
\text { (Volts) }\end{array}$ & $\begin{array}{c}V_{o}^{* * *} \\
\text { (Volts) }\end{array}$ \\
\hline Protons & 3 & $800 \mathrm{nC}$ & $\begin{array}{l}1 / 4 \\
1 / 5 \\
1 / 6 \\
\end{array}$ & $\begin{array}{cc}9.99 & \mathrm{nC} \\
12.5 & \mathrm{nC} \\
15.0 & \mathrm{nC} \\
\end{array}$ & $\begin{array}{l}25.0 \\
31.2 \\
37.5 \\
\end{array}$ & $\begin{array}{l}19.2 \\
24.0 \\
28.8 \\
\end{array}$ \\
\hline $\begin{array}{l}\text { Polarized } \\
\text { Protons }\end{array}$ & 3 & $107 \mathrm{nC}$ & $\begin{array}{l}1 / 4 \\
1 / 5 \\
1 / 6 \\
\end{array}$ & $\begin{array}{ll}1.33 & \mathrm{nC} \\
1.66 \mathrm{nC} \\
2.00 \mathrm{nC} \\
\end{array}$ & $\begin{array}{l}3.33 \\
4.16 \\
5.00 \\
\end{array}$ & $\begin{array}{l}2.56 \\
3.20 \\
3.84 \\
\end{array}$ \\
\hline C & 3 & $\begin{array}{l}17.3 \mathrm{nC} \\
4.32 \mathrm{nC}\end{array}$ & $\begin{array}{c}1 / 4 \\
1 / 5 \\
1 / 6 \\
0.444 \\
2 / 3 \\
\end{array}$ & $\begin{array}{l}0.216 \mathrm{nC} \\
0.270 \mathrm{nC} \\
0.324 \mathrm{nC} \\
0.121 \mathrm{nC} \\
0.081 \mathrm{nC} \\
\end{array}$ & $\begin{array}{l}0.54 \\
0.67 \\
0.81 \\
0.30 \\
0.20 \\
\end{array}$ & $\begin{array}{l}0.42 \\
0.52 \\
0.62 \\
0.23 \\
0.16 \\
\end{array}$ \\
\hline$S$ & 3 & $\begin{array}{l}11.2 \mathrm{nC} \\
2.80 \mathrm{nC}\end{array}$ & $\begin{array}{c}1 / 4 \\
1 / 5 \\
1 / 6 \\
0.444 \\
2 / 3 \\
\end{array}$ & $\begin{array}{l}0.140 \mathrm{nC} \\
0.175 \mathrm{nC} \\
0.210 \mathrm{nC} \\
0.079 \mathrm{nC} \\
0.052 \mathrm{nC}\end{array}$ & $\begin{array}{l}0.35 \\
0.44 \\
0.52 \\
0.20 \\
0.13 \\
\end{array}$ & $\begin{array}{l}0.27 \\
0.34 \\
0.40 \\
0.15 \\
0.10 \\
\end{array}$ \\
\hline $\mathrm{Cu}$ & $\begin{array}{l}3 \\
12\end{array}$ & $\begin{array}{l}11.2 \mathrm{nC} \\
2.80 \mathrm{nC}\end{array}$ & $\begin{array}{c}1 / 4 \\
1 / 5 \\
1 / 6 \\
0.444 \\
2 / 3 \\
\end{array}$ & $\begin{array}{l}0.140 \mathrm{nC} \\
0.175 \mathrm{nC} \\
0.210 \mathrm{nC} \\
0.079 \mathrm{nC} \\
0.052 \mathrm{nC} \\
\end{array}$ & $\begin{array}{l}0.35 \\
0.44 \\
0.52 \\
0.20 \\
0.13 \\
\end{array}$ & $\begin{array}{l}0.27 \\
0.34 \\
0.40 \\
0.15 \\
0.10 \\
\end{array}$ \\
\hline I & 12 & $\begin{array}{l}10.2 \mathrm{nC} \\
2.55 \mathrm{nC}\end{array}$ & $\begin{array}{c}1 / 4 \\
1 / 5 \\
1 / 6 \\
0.444 \\
2 / 3 \\
\end{array}$ & $\begin{array}{l}0.127 \mathrm{nC} \\
0.159 \mathrm{nC} \\
0.191 \mathrm{nC} \\
0.072 \mathrm{nC} \\
0.048 \mathrm{nC} \\
\end{array}$ & $\begin{array}{l}0.32 \\
0.40 \\
0.48 \\
0.18 \\
0.12 \\
\end{array}$ & $\begin{array}{l}0.24 \\
0.31 \\
0.37 \\
0.14 \\
0.09 \\
\end{array}$ \\
\hline $\mathrm{Au}$ & 12 & $5.63 \mathrm{nC}$ & $\begin{array}{c}1 / 4 \\
1 / 5 \\
1 / 6 \\
0.444 \\
2 / 3\end{array}$ & $\begin{array}{l}0.070 \mathrm{nC} \\
0.088 \mathrm{nC} \\
0.105 \mathrm{nC} \\
0.040 \mathrm{nC} \\
0.026 \mathrm{nC}\end{array}$ & $\begin{array}{l}0.18 \\
0.22 \\
0.26 \\
0.10 \\
0.06\end{array}$ & $\begin{array}{l}0.14 \\
0.17 \\
0.20 \\
0.08 \\
0.05\end{array}$ \\
\hline
\end{tabular}

* The peak voltage $\left(V_{\text {peak }}\right)$ is calculated for the maximum specified beam displacement of $30 \mathrm{~mm}$. In addition, the above tabulated voltages assume a "day 1" PUE capacitive loading as in Figure 2.

** the "charge per bunch" is the total charge (from Table 1) divided by the harmonic number, $h$. For polarized protons, the total charge accumulated (for one AGS cycle) is used.

*** $\quad V_{o}$ is the maximum voltage on a PUE for a transversely centered beam. 


\section{ACKNOWLEDGEMENT:}

The review of this technical note by $\mathrm{R}$. Thomas is gratefully acknowledged. Subsequent discussions on this topic have been both informative and intriguing.

\section{REFERENCES}

1. Booster Design Manual, BNL, Revision 1, October 1988.

2. L. W. Couch, Digital and Analog Communication Systems, second edition, New York: Macmillan, 1987.

3. Reference Data for Engineers: Radio, Electronics, Computer and Communications, seventh edition, Indianapolis: Howard W. Sams, 1985.

4. CRC Standard Mathematical Tables, 25th edition, Boca Raton: CRC Press, 1979. 


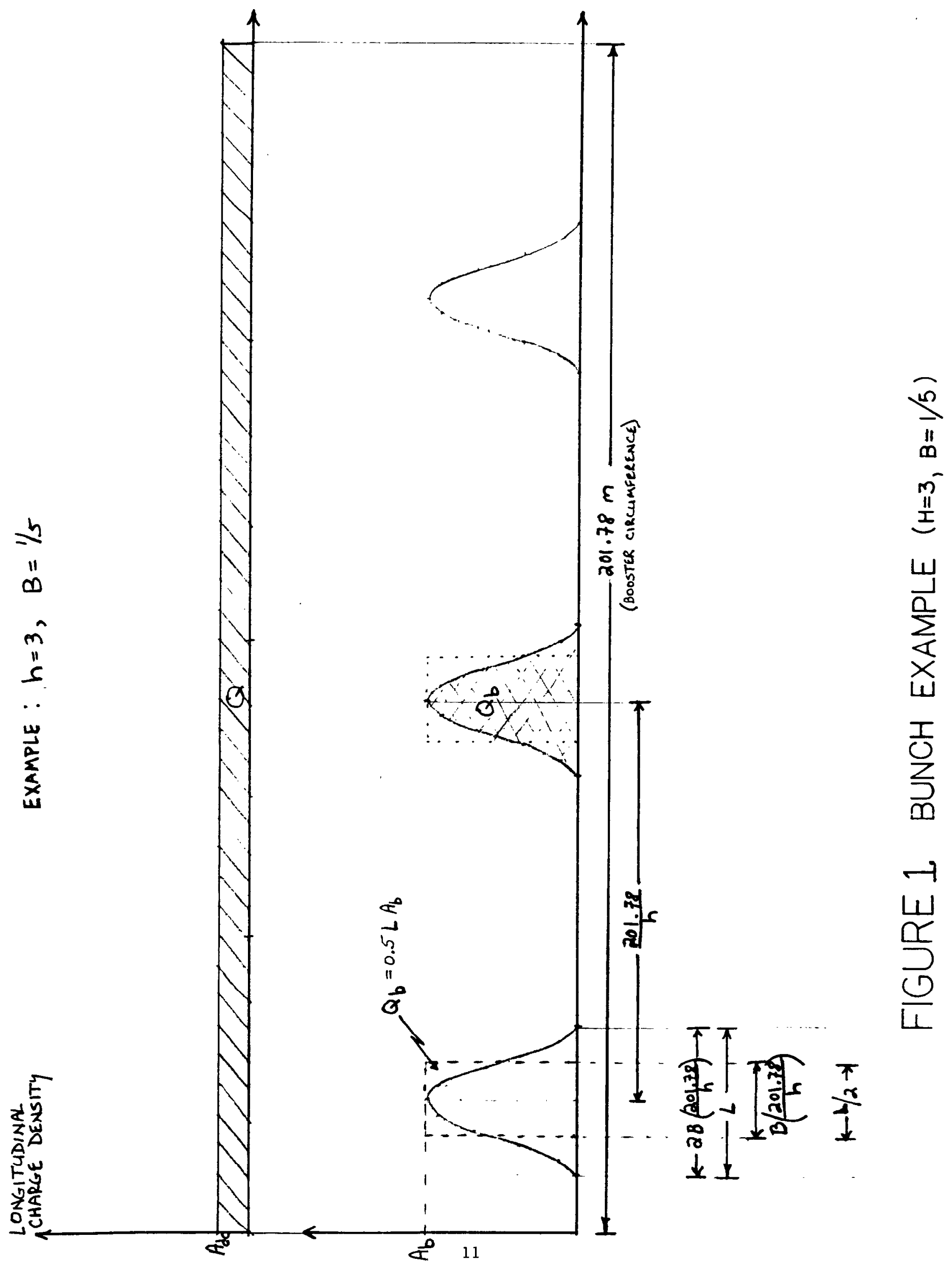



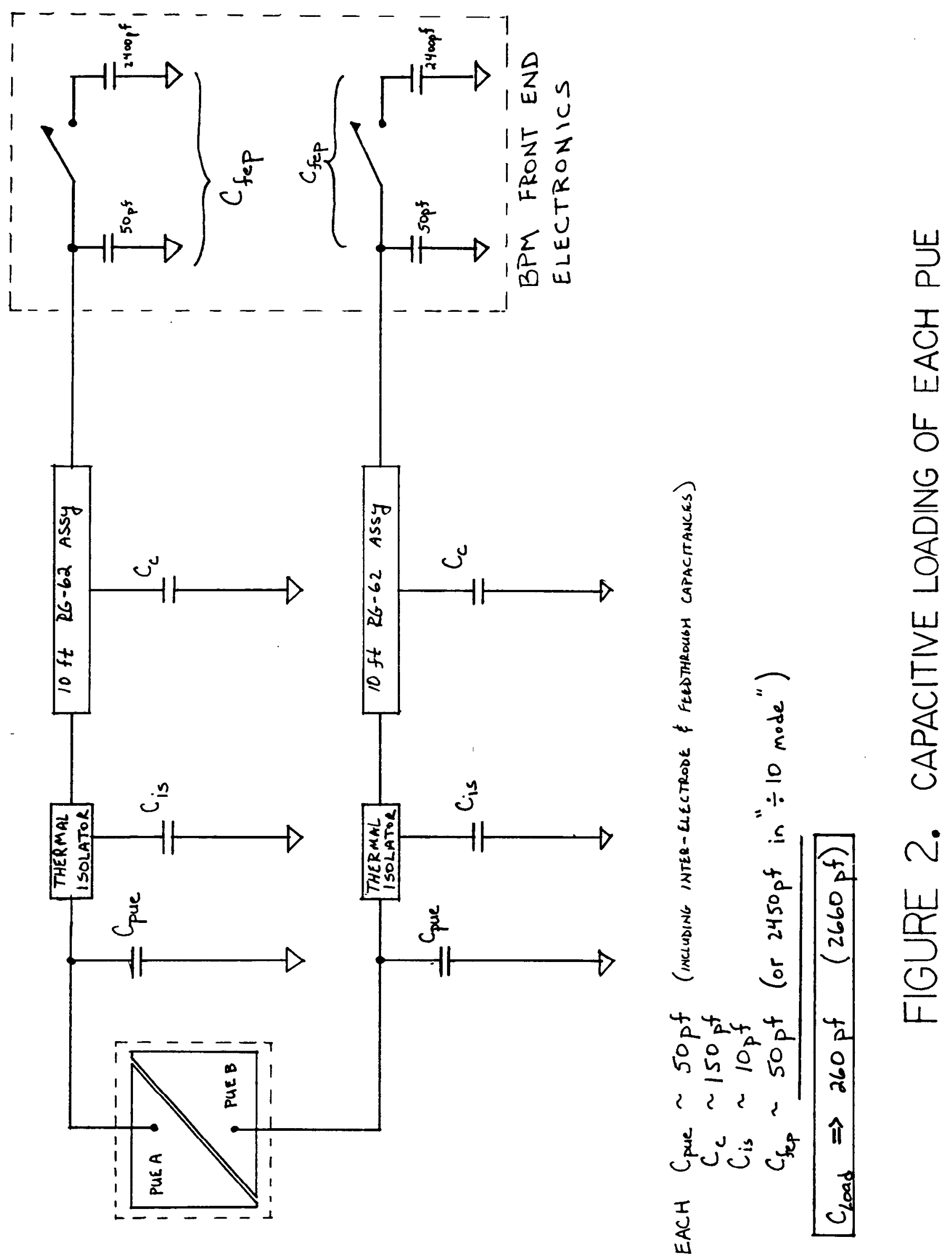


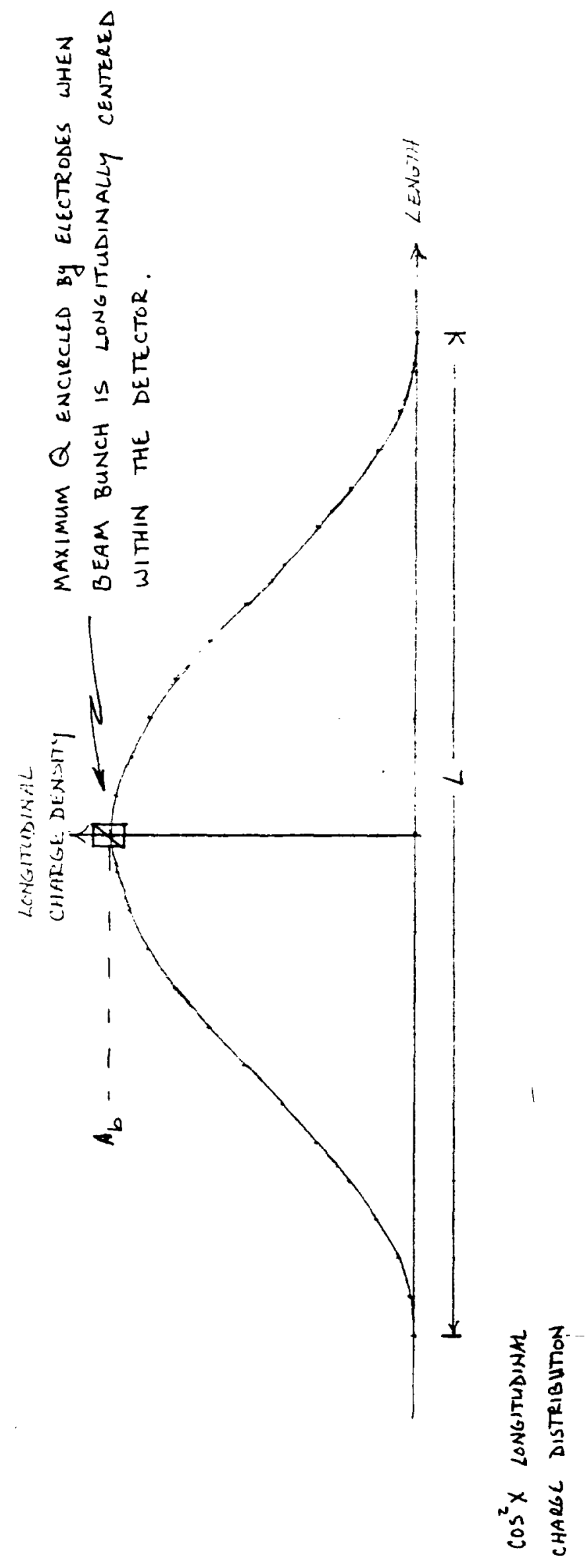


APPENDIX A : CALCULATION OF CHARGE ENCIRCLED BY DETECTOR

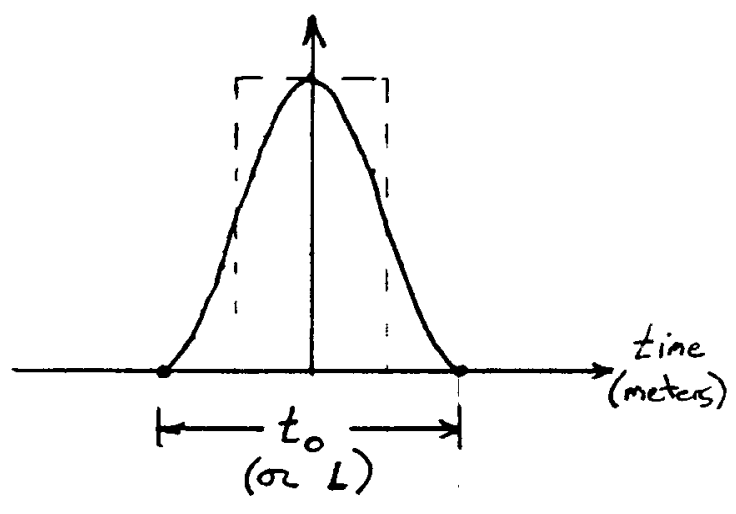

$\stackrel{\rightarrow \cdot \frac{201.78}{h}}{\rightarrow}$

$1-2 B \frac{201.72}{h} \longrightarrow$
Ab $\int \cos ^{2}[a x] d x=\frac{x}{2}+\frac{1}{4 a} \sin [2 a x]$

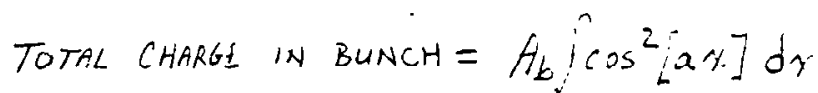

$Q_{b}=A_{b}\left\{\frac{x}{2}+\frac{1}{4 a} \sin [2 a x]\right\}{ }_{-B \cdot 201.78 \% h}^{+B \cdot 201.78 / h}$

PUES IN DETECTOR ARE $0.21 \mathrm{M}$ IN LENGTH.

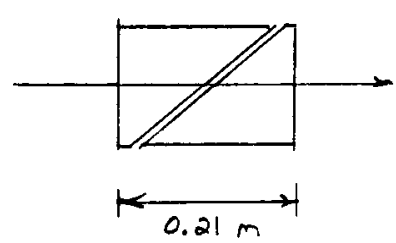

$Q_{\text {det }}=\begin{aligned} \text { total charge } \\ \text { inside deteitor }\end{aligned}$

1. Choose ' $a$ ' such that $\cos ^{2}(a x)$ GOES TO O AT $t /-\pi / 2$

$$
\cos ^{2} a x \rightarrow 0 \rightarrow a x=\pi / 2 \rightarrow \pi /==a\left(B \cdot \frac{201 \cdot 78}{h}\right) \rightarrow a=\frac{\pi}{2} \frac{h}{B \cdot 201 \cdot 78}
$$

2. USE AREA UNDER $\cos ^{2}(a x)$ TO FIND $A_{b}$ :

$$
\begin{aligned}
Q_{b} & =A_{b}\left[\frac{x}{2}+\frac{1}{4} \frac{2 B}{\pi} \frac{201.78}{h} \sin \left(2 \frac{\pi}{2} \frac{h}{B \cdot 201.78} x\right)\right]_{-B \cdot \frac{201.78}{h}}^{h} \\
& =A_{b}\left(\frac{E \cdot 201.78}{h}\right)\left(1+\frac{1}{\pi} \sin (\pi)\right) \\
Q_{b} & =A_{b}\left(\frac{B \cdot 201.78}{h}\right) \longrightarrow A_{b}=\frac{Q_{b}}{B(201.78 / h)}
\end{aligned}
$$

3. INTEERATE OVER DETLCTOR LENGTH TO FIND CHAREE ENEIRCLES BY DETLCTOE:

$$
\begin{aligned}
Q_{d e t} & =A_{b} \int_{-0.21 / 2}^{+0.21 / 2} \cos ^{2}(a x) d x=\frac{Q_{b}}{B(201.78 / h)} \int_{-0.105}^{+0.105} \cos ^{2}\left(\frac{\pi}{2} \frac{h}{B .201 .78} x\right) d x \\
& =\frac{Q_{b}}{B(201.78 / h)}\left[k\left(\frac{0.105}{7}\right)+2 \frac{1}{4} \frac{2 B \cdot 201.78}{\pi} \sin \left(2 \frac{\pi}{7} \frac{b}{B .201 .78} 0.105\right)\right]
\end{aligned}
$$

$$
Q_{\operatorname{det}}=Q_{b}\left[\frac{0.105}{B(201.78 / h)}+\frac{1}{\pi} \sin \left(\pi \frac{0.105}{B(201.78 / h)}\right)\right]
$$

